\title{
High-Payoff Space Transportation Design Approach with a Technology Integration Strategy
}

\author{
C. M. McCleskey ${ }^{1}$ and R. E. Rhodes and ${ }^{2}$ \\ NASA Kennedy Space Center, Florida, 32899 \\ T. Chen ${ }^{3}$ \\ NASA Marshall Space Flight Center, Huntsville, Alabama, 35812 \\ and \\ J. Robinson ${ }^{4}$ \\ The Boeing Company, Huntington Beach, California, 92647
}

\begin{abstract}
A general architectural design sequence is described to create a highly efficient, operable, and supportable design that achieves an affordable, repeatable, and sustainable transportation function. The paper covers the following aspects of this approach in more detail: (1) vehicle architectural concept considerations (including important strategies for greater reusability); (2) vehicle element propulsion system packaging considerations; (3) vehicle element functional definition; (4) external ground servicing and access considerations; and, (5) simplified guidance, navigation, flight control and avionics communications considerations. Additionally, a technology integration strategy is forwarded that includes: (a) ground and flight test prior to production commitments; (b) parallel stage propellant storage, such as concentric-nested tanks; (c) high thrust, LOX-rich, LOX-cooled first stage earth-to-orbit main engine; (d) non-toxic, day-of-launch-loaded propellants for upper stages and in-space propulsion; (e) electric propulsion and aero stage control.
\end{abstract}

${ }^{1}$ Aerospace Technologist, Engineering Directorate, Kennedy Space Center/NE-D2, and AIAA Senior Member.

${ }^{2}$ Aerospace Technologist, Engineering Directorate, Kennedy Space Center/NE-D2, and AIAA Senior Member.

${ }^{3}$ Insert Job Title, Department Name, Address/Mail Stop, and AIAA Member Grade for third author.

${ }^{4}$ Insert Job Title, Department Name, Address/Mail Stop, and AIAA Member Grade for fourth author (etc). 


\title{
High-Payoff Space Transportation Design Approach with a Technology Integration Strategy
}

\author{
C. M. McCleskey ${ }^{1}$ and R. E. Rhodes ${ }^{2}$ \\ NASA Kennedy Space Center, Florida, 32899 \\ T.T. Chen ${ }^{3}$ \\ NASA Marshall Space Flight Center, Huntsville, Alabama, 35812 \\ J.W. Robinson ${ }^{4}$ \\ The Boeing Company (ret), Huntington Beach, Calffornia, 92647
}

This paper describes a general approach for creating architectural concepts that are highly efficient, operable, and supportable, in turn achieving affordable, repeatable, and sustainable space transportation. The paper focuses on the following: (1) vehicle architectural concept considerations (including important strategies for greater reusability); (2) vehicle element propulsion system packaging considerations, including integrated main and auxiliary propulsion systems; (3) vehicle element functional integration; (4) ground element functional integration; (5) simplified and automated electrical power and avionics integration; and, (6) ground and flight test prior to production commitments. Additionally, we have provided four essential technologies enabling the high payoff design approach: (a) parallel stage propellant storage, such as concentric-nested tanks, for more efficient space vehicle design and operation; (b) high thrust, LO2-rich, LO2-cooled first stage earth-to-orbit main engine; (c) non-toxic, day-of-launch-loaded propellants for upper stages and in-space propulsion; and (d) electric propulsion and flight controls.

$\begin{array}{ll}\text { ASTF } & =\text { Aft Skirt Test Facility } \\ \text { CH }_{4} & =\text { Methane } \\ \text { EHA } & =\text { Electro-Hydrostatic Actuator } \\ \text { EMA } & =\text { Electro-Mechanical Actuators } \\ \text { ETO } & =\text { Earth-to-Orbit } \\ \text { GRC } & =\text { Glenn Research Center } \\ \text { GSE } & =\text { Ground Support Equipment } \\ \text { HMF } & =\text { Hypergolic Maintenance Facility } \\ I_{s p} & =\text { Specific Impulse } \\ \text { KSC } & \text { = Kennedy Space Center } \\ \text { L/D } & =\text { Length-to-Diameter ratio } \\ \text { LH2 } & \text { =Liquid Hydrogen } \\ \text { LO2 } & \text { =Liquid Oxygen } \\ \text { LRU } & \text { =Line Replacement Unit }\end{array}$

\section{Nomenclature}

$\begin{array}{ll}\text { MPS } & =\text { Main Propulsion System } \\ \text { MR } & =\text { Mixture Ratio } \\ \text { O\&M } & =\text { Operations and Maintenance } \\ \text { OML } & =\text { Outer Mold Line } \\ \text { RP-1 } & =\text { Rocket Propellant }-1 \\ \text { SCAPE } & =\text { Self-Contained Atmospheric Protective } \\ & \text { Ensemble } \\ \text { SPST } & =\text { Space Propulsion Synergy Team } \\ \text { SRB } & =\text { Solid Rocket Booster } \\ \text { SSME } & =\text { Space Shuttle Main Engine } \\ \text { TPM } & =\text { Technical Performance Measures } \\ \text { TPS } & =\text { Thermal Protection System } \\ \text { TVC } & =\text { Thrust Vector Control }\end{array}$

\footnotetext{
${ }^{1}$ Aerospace Technologist, Engineering Directorate, NASA Kennedy Space Center, mail code NE-D1, and AIAA Senior Member.

${ }^{2}$ Aerospace Technologist, Engineering Directorate, NASA Kennedy Space Center, mail code NE-D1, and AIAA Senior Member.

${ }^{3}$ Lead Aerospace Engineer, Spacecraft and Vehicle Systems Department, NASA Marshall Space Flight Center, mail code EV-91, and AIAA Senior Member.

${ }^{4}$ The Boeing Company (retired); chairman, Space Propulsion Synergy Team, and AIAA Associate Fellow. 


\section{Introduction}

A six-step sequential process is suggested to provide a general architectural design sequence to create a highly efficient, operable, and supportable design that achieves an affordable and economically sustainable transportation function. The six critical, sequential steps are·

Six Critical Steps to an Affordable, Economically Sustainable System Design

1. Simplify the vehicle/ground system architecture

2. Efficiently package each vehicle element's propulsion system (i.e., tank, engine and compartment layouts)

3. Integrate vehicle element functions into the lowest number of subsystems/components with minimum ground support requirements

4. Integrate ground element functions into the lowest number of work stations, facilities, and support equipment

5. Simplify avionics and flight control design into minimum components, then, power and automate what's left

6. Extensively flight test to demonstrate accomplishment of all production and operations needs and objectives for full operational system capability with the affordability objective met

These steps are important to perform during early conceptual design to avoid the accumulation of unaffordable design, development, production, and ground operations work. Through adherence to these steps, one can also avoid time delays that cause added expenditures, as well, and thus achieve the objectives of life cycle affordability and operational sustainability.

Each of the steps discuss the specifics of the approach followed by a section identifying how each step addresses technical criteria that influence space transportation affordability and sustainability. This paper uses the list of criteria developed by the Space Propulsion Synergy Team (SPST), a NASA-sponsored volunteer group of experienced government, industry and academia colleagues in the space propulsion community. ${ }^{1}$

Specifically, the SPST identified eighteen (18) highly influential criteria as design drivers of space transportation affordability and sustainability. Selected from among 64 candidate design drivers, these eighteen measurable criteria were previously determined by the SPST to be the most important to understand and control during the design cycle for achieving life cycle affordability. An in-depth treatment of these criteria and their influence on life cycle affordability and sustainability are provided in the referenced Joint Propulsion Conference paper. $^{2}$

This paper adds another criterion to these eighteen-reusability. For the purposes of this paper, reusability is the ability of a system, or parts of a system, to be reused for multiple flights.

A system with low reusability requires a high degree of work for its next flight. A system with high reusability is assumed to be one that fully retains its functional integrity between flights, and thus little or no work is required other than payload handling and propellant servicing. Highly reusable systems are more affordable by (1) minimizing routine purchases of high-value flight equipment by its owner-operator, (2) reducing routine maintenance expense, and (3) increasing system productivity through shorter processing durations. Therefore, we can logically conclude that highly reusable system design techniques and advanced technologies are needed to enable affordable and sustainable space transportation.

The affordability benefits due to reusability become less clear when comparing low reusability systems (e.g., ocean-retrieved elements) with fully expendable systems.

The total list of nineteen (19) criteria (i.e., the 18 derived by the SPST plus the reusability criterion explained above), and their correlation with key life cycle affordability parameters derived by the authors, is shown in Table 1 . The paper concludes by identifying specific technologies and design approaches that support the steps described in achieving the overall objectives of affordability and economic sustainability. 


\section{Step 1. Simplify the Vehicle Architecture}

\section{A. Discussion/Specifics}

Simplify the vehicle by minumizing the number of unique vehicle elements and maximize reusability in those that remain in the concept.

This keeps the number of production and operations ground stations to a minimum, and therefore, holds the marginal and fixed operating costs to a minimum. A high degree of reusability allows the owner-operator to minimize the requirement for routinely purchasing high-value flight equipment and replacement parts. The minimum number of elements minimizes unique annual fixed costs associated with the production, supply, servicing, and maintenance of each unique stage or element. Finally, a simplified flight system made up of a minimum number of elements enables a simplified ground system. A simplified ground system not only reduces fixed infrastructure support costs, but also decreases direct operating costs per flight and greater flight throughput by reducing work content and eliminating time-consuming work. As a result of the reduced work and time, the system utilization, affordability, and sustainability for the equipment owner-operator are all improved.

\section{B. Specific Engineering Criteria Addressed for Improvement}

Step 1 directly addresses about half of the nineteen (19) engineering criteria for achieving affordable and sustainable space transportation systems (reference Error! Reference source not found. for specific correlations to affordability);

- Percentage of elements and systems that are highly reusable

- Total number of separate identified vehicle propulsion systems and/or separate stages

- Total number of flight tanks in the architecture

- Number of maintenance actions unplanned before or between missions

- Number of maintenance actions planned before or between missions

- Total number of traditional ground interface functions required

- Total number of vehicle element-to-element support systems

- Number of flight vehicle servicing interfaces

- Number of confined/closed compartments

- Number of mechanical element mating operations

\section{Step 2. Efficiently Package Each Vehicle Element's Propulsion System}

\section{A. Discussion/Specifics}

Achieve a far more compact vehicle design whose cryogenic propulsion systems are far simpler to operate inflight and on the ground than current design approaches

The design strategy contains a number of specifics for achieving this, and is enabled through:

1. Use of minimum number of main and auxiliary propellant commodities, preferably confined to dav-oflaunch-loaded oxygen and hydrogen only. The idea is to keep the accumulation of design effort, recurring production work, and ground processing time and expense to a minimum. Separate propulsion systems are additive to theses life cycle cost elements.

2. Keep ground interface connections close to ground level to avoid a series of elevated, articulating umbilicals-particularly, lift-off umbilicals (i.e., those that remain connected until vehicle first-motion or, $\underline{T-0}$ umbilicals). Avoiding large structures keeps ground system development and maintenance costs down. When such systems are outfitted with active mechanical, plumbing and electrical systems, the development, maintenance and operations costs go up. Also, the responsiveness of the system to produce a launch goes up.

3. Avoid production complexities, operational propellant loading complextites, and safety risks of specifyung common-bulkhead, tandem tank arrangements and separate auxiliary propulsion systems.

4. Use concentric-nested propellant tanks arranged such that complex feed systems and other external subsystems are eliminated (note concentric-nested means one tank is concentrically arranged inside another, but no common wall). This approach eliminates long feed lines and a number of active support subsystems for the propulsion function; e.g., long propellant feed lines for the pump feed system, LO2 "pogo" suppression system, anti-geysering and thermal conditioning sub-systems. Furthermore, concentricnested tank concepts minimize the volume and weight of the total system. As such, the approach has wide and far-reaching architectural implications across a number of space transportation applications and across the space transportation life cycle. It also allows the incorporation of advanced concepts such as integrating

American Institute of Aeronautics and Astronautics 071311 
the turbo-pump into the main propellant tank sump, further avoiding the need for added sub-systems previously mentioned.

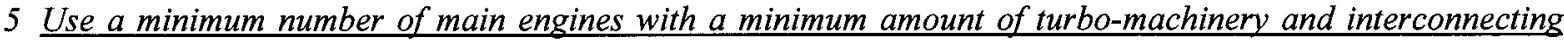
main propulsion system plumbing. The more main engines (meaning devices incorporating feed turbomachinery, combustion chambers, and exhaust nozzles) there are in the system, the more interconnecting plumbing, avionics, software and opportunities for reliability problems accumulate. This rapidly expands the effort required to: design the main propulsion system, develop and test, continually manufacture (particularly if expended each flight), process on the ground, and control risk in flight.

6. Use electric propellant valve actuation and eliminate distributed hydraulic and pneumatic primary and backup systems from all engine and propellant system controls (including thrust vector control, but only if differential required). This approach avoids numerous support systems for the propellant valve controls and/or gimbaled engines and reduces the number of support systems for the flight vehicle and ground support equipment. It also means fewer parts to produce and less assembly work leading to more flights in shorter times with less effort.

7. In the longer-term, consider using LO2-rich, LO2-cooled main engine combustion for first stage earth-toorbit propulsion that adjusts the mixture ratio back toward stoichiometric ratio as the thrust requirement is reduced during ascent. This concept reduces the combined propellant tank volume, and hence reduces vehicle length and dry weight. This allows a more efficient design for both flight and ground operations. It also better enables the design criteria of minimum number of propellants since it avoids having to use unique, high thrust propellant combinations applicable to lower-altitude, first stage flight only. Use of solid boosters or kerosene is generally seen as beneficial for low-altitude, first stage flight where specific impulse is traded for higher thrust. This concept uses a common set of propellants throughout the ascent phase and varies the thrust $/ I_{s p}$ characteristics during flight with a minimum number of dedicated systems.

\section{B. Specific Engineering Criteria Addressed for Improvement}

Step 2 enables or directly addresses at least twelve (12) of the nineteen (19) engineering criteria for achieving affordable and sustainable space transportation systems (reference Table 1 for specific correlations to affordability);

- Total number of separate identified vehicle propulsion systems and/or separate stages

- Percentage of elements and systems that are highly reusable

- Total number of traditional ground interface functions required

- Number of flight vehicle servicing interfaces

- Number of different fluids required

- Number of safety driven functional requirements to maintain safe control of systems during flight and ground operations

- Number of confined/closed compartments

- Number of safety driven limited access control operations

- Number of maintenance actions unplanned before or between missions

- Number of maintenance actions planned before or between missions

- Number of commodities used that require medical support operations and routme training

- Number of Critcality 1 system and failure analysis modes

\section{Step 3. Integrate Vehicle Element Functions into the Lowest Number of Subsystems/Components}

\section{A. Discussion/Specifics}

Create a generic functional systems breakdown structure for each concelved vehicle element, and combine (or integrate) as many functions into singular systems to provide a minimum of standalone, dedicated subsystems. ${ }^{3}$ This will minimize the number of accumulated subsystems and supporting components for a given set of required functions. For example, combine various propulsion and power functions with common propellants and fluid commodities to avoid separate fill and drain, storage and distribution subsystems, ground interfaces, and GSE. Also, use technical approaches that inherently require fewer separate support subsystems to perform the function (e.g., use electric actuation to displace distributed hydraulics and its support subsystems and GSE). In so doing, the cumulative design and development effort for both flight and ground support systems is greatly reduced. The recurring production effort is likewise reduced, along with the attendant number of separate suppliers required to 
sustain the system. The recurring ground operations work and processing time are reduced, as well as recurring labor, materials, and other direct costs.

\section{B. Specific Engineering Criteria Addressed for Improvement}

Step 3 enables or directly addresses a large number of the nineteen (19) engineering criteria for achieving affordable and sustainable space transportation systems (reference Table 1 for specific correlations to affordability);

- Total number of flight tanks in the architecture

- Total number of separate identified vehicle propulsion systems andior separate stages

- Total number of traditional ground interface functions required

- Number of flight vehicle servicing interfaces

- Number of different fluids required

- Number of safety driven functional requirements to maintain safe control of systems during flight and ground operations

- Number of confined/closed compartments

- Number of safety driven limited access control operations

- Number of maintenance actions unplanned before or between missions

- Number of maintenance actions planned before or between missions

- Number of commodities used that require medical support operations and routine training

- Number of Criticality 1 system and failure analysis modes

- Number of safing operations at landing (for reusable elements)

Step 4. Integrate ground element functions into the lowest number of work stations, facilities, and support equipment

\section{A. Discussion/Specifics}

Keep routine external ground servicing and access requirements simple and to a minimum; e.g., strive for no masts or towers:

The design strategy contains a number of specifics for achieving this, and is enabled through:

1. Avoid breaking the functional integrity of any flight systems during ground turnaround operations. For highly reusable system designs, the objective is to avoid electrical and plumbing disconnections, along with mechanical system disconnections that would require re-rigging, re-calibration, re-alignment, and functional checkout. Minimize any operator "closeout" activity by design. This will significantly reduce routine ground operations work and time required to produce a flight.

2. Require the flight systems to be designed for maintainability as a means for achieving reliability and safety objectives. This avoids the need to go into a maintenance station during ground turnaround operations.

3. Locate internal line replacement units (LRUs) near outer mold-line to avold all internal access for installation and/or routine change-out. Doing so eliminates the need for internal access kits for routine operations, conditioned air, controlled personnel entry and drag-on lighting.

4. Strive to remove as many closed vehicle compartments as possible. This approach minimizes subsystem hardware and routine ground operations required in such compartments, i.e. purges and hazardous gas detection subsystems This will also support the objective to avoid the need to go into a dedicated maintenance station for routine ground turnaround operations (see Figure 1).

5. Avold vehicle element design complexity when other passive system design techniques can achieve the same results, potentzally with a net weight reduction Examples: (1) open truss vs. enclosed compartment, or (2) radiation-cooled vs. forced cooling, or (3) MPS head start vs. ground-supplied turbine spin system. Retaining existing functional and hardware complexity also reduces the overall system reliability and safety of flight.

6. Integrate and use main propellant tanks for auxiliary propulsion and power services wherever practical Avoid dedicated tank sets. These require separate subsystem designs and added design, integration, and ground operations and associated logistics chain that accumulate both production and ground operations work content. The design objective is to keep the cumulative amount of plumbing systems that the production line and the operator encounter to an absolute minimum. Provide enough margins to fully account for plumbing interconnects.

7. Minimize the number of dedicated fluids and gases as well as the number of separate speciallzed fluid purtties required. All subsystems must be coordinated on this during design definition.

American Institute of Aeronautics and Astronautics 
8 Locate the remaining vehicle ground servicing points near ground level, and avoid elevated fluid system servicing and purge points requiring towers with dedicated service arms and access platforms.

9. Avoid T-0 umbilicals. However, all unavoidable day-of-launch propellants should have their flight-toground interfaces at ground level to avoid system complexities associated with elevated services. umbilicals, etc.

10. Load all stage propellants (including spacecraft modules) on day of launch Avoid assembly operations involving stages and modules with loaded and fully pressurized fluld systems which are considered an unsafe practice for personnel safety. Non-propellant fluids, e.g. life support fluids and gases, should be loaded prior to day of launch.

B. Specific Engineering Criteria Addressed for Improvement

Step 4 enables or directly addresses a large number of the nineteen (19) engineering criteria for achieving affordable and sustainable space transportation systems (reference Table 1 for specific correlations to affordability);

- Percentage of elements and systems that are highly reusable

- Number of maintenance actions unplanned before or between missions

- Number of maintenance actions planned before or between missions

- Total number of flight tanks in the architecture

- Total number of traditional ground interface functions required

- Number of flight vehicle servicing interfaces

- Number of different fluids required

- Number of safety driven functional requirements to maintain safe control of systems during flight and ground operations

- Number of confined/closed compartments

- Number of safety driven limited access control operations

- Number of commoditles used that require medical support operations and routine training

- Number of Criticality 1 system and failure analysis modes

- Number of safing operations at landing (for reusable elements)

\section{Step 5. Simplify avionics and flight control design into minimum components; then, power and automate what's left}

\section{A. Discussion/Specifics}

Steps 1 through 4 have set the stage for a vehicle design that maximizes functionality with a minimum of hardware systems. The next step is to bring those systems to life by powering them, enabling them to communicate with other flight systems and/or flight crews, and with ground systems and/or ground crews. This step also requires attention to the principles of minimizing complexity. Finally, automate what is left by applying savings amortized in the first four (4) steps of this process.

The design strategy contains a number of specifics for achieving this, and is enabled through:

1. Use simple and dependable flight control mechanisms that do not require routine fluld and/or gas servicing during ground operations. Similar to approach in Step 3, but applies to electric power support of flight controls that are less expensive to design, produce, operate, and sustain than existing fluid and gas powered systems for flight control actuation.

2. Keep the number of dedicated avionics boxes to an absolute minimum (achlevable if all of the above is adhered to) to the point where no dedicated active avionics cooling subsystems are required. The thermal threshold that drives passive cooling to active cooling for a suite of avionics components must be understood, managed, and constantly monitored and controlled throughout the design process. Attention and visibility must involve all subsystem designers and be made a hard and fast design requirement. One way to do this is to keep the number of dedicated avionics boxes to an absolute minimum (achievable if all of the above is adhered to) to the point where no dedicated active avionics cooling subsystems are required. In so doing, an avionics system not requiring added active thermal control systems can help keep the cumulative DDT\&E, production, and operations costs down to a minimum. Without such attention, avionics systems are likely to require the use of complex cold plates and supporting working fluids, flight and ground support equipment, and work involved with their design and upkeep. 
3. Build-in enough mass margins to account for avionics cable lengths and interconnectivity hardware. Not doing so requires added effort and high risk of expensive design, production and ground operations re-work. This can delay operational deployment and create less flexibility for the owner-operator to leave the cabling alone for a variety of customers. With little or no margin, the operator is often forced to spend time and money optimizing the cabling to maintain propulsion margin for a particular payload.

4. Avoid specialized ground power. Standardize the ground power to a single interface and build in, from the beginning, enough mass margins to convert power on board. The time and expense involved in ground systems design and development can be reduced, along with added hook-ups to ground services (see Figure 2).

5. Build in remote autonomous avionics functional verification everv time the systems are powered-up. This can dramatically increase ground operations efficiencies for launch vehicles and spacecraft. Without this built-in design feature, the ground operators are left to play a game of "twenty questions", so to speak, just to determine whether functional integrity is available to continue with critical servicing and launch operations. This provides autonomous verification that the vehicle's active systems have retained functional integrity: i.e., that full electrical power, electronic signal, and software integrity exists upon power-up prior to continuing critical operations. Modern computer peripherals and automobiles do this to a greater degree upon power-up for their operators, for instance, than seen in most modern launch vehicles and spacecraft. The objective is to automatically determine that there are no electrical shorts or opens, and that no inadvertent software errors have been introduced. A greater degree of vehicle availability, achieved through more responsive flight system power-up times, increases affordability by achieving greater flight rate capability for a given set of fixed and variable operating costs.

\section{B. Specific Engineering Criteria Addressed for Improvement}

.Step 5 enables or directly addresses a large number of the nineteen (19) engineering criteria for achieving affordable and sustainable space transportation systems (reference Table 1 for specific correlations to affordability);

- Number of separate electrical supply interface functions required

- Percentage of elements and systems that are highly reusable

- Percent of all systems not automated

- Number of maintenance actions unplanned before or between missions

- Number of maintenance actions planned before or between misstons

\section{Step 6. Extensively Test/Adjust the Design to Qualify the System and Achieve the Objectives}

\section{A. Discussion/Specifics}

Extensively qualify the components, verify $\&$ validate the systems, and flight test the vehicle to prove accomplishment of all needs and objectives prior to commitment to full operational capability and/or production; then continuously improve to maintain pre-eminence and competitiveness. Specifically,

1. Prove-out design assumptions for simplicity and build technical and managerial confidence in a simple, robust system prior to committing to production.

2. Allow the flight test program to schedule improvements in the system design pror to committing to production. This is done to avoid production cost impacts to design changes intended to verify for the owner-operator that it can meet operability and supportability objectives.

3. Maintain a separate, developmental component, subsystem, svstem, and flight test capability that is offline from operational transportation service; do not put these in the serial-critical path of the owner-operator of the system. The owner-operator should not be expected to interrupt their transportation service to make risky changes and conduct flight experiments. Nor should technical changes to the systems design be required to impact production costs which should be surfaced in the offline test mode. A separate effort to demonstrate upgraded capabilities will mitigate any added operational program risk from design improvement changes. 


\section{B. Specific Engineering Criteria Addressed for Improvement}

Step 6 enables or directly addresses a large number of the nineteen (19) engineering criteria for achieving affordable and sustainable space transportation systems (reference Table 1 for specific correlations to affordability);

- Percentage of elements and systems that are highly reusable

- Number of maintenance actions unplanned before or between missions

- Number of maintenance actions planned before or between missions

- Number of Criticality 1 system and failure analysis modes

\section{Four Essential Technologies Enabling the High Payoff Design Approach}

\section{A. Concentric-Nested Propellant Tanks for Launch Vehicle Stages and Spacecraft}

To simply the architectural design, in-depth consideration should be given to using concentric-nested main propellant tanks, where the inner wall of the external of the two tanks is integral to the structure of the space vehicle. Such configurations would use at least one toroidal tank configuration located on the exterior to take the vehicle and engine structural loads (depending on how many stages employ this technique). This enables the overall vehicle architecture to achieve a far more compact vehicle structure whose cryogenic propulsion system is far simpler to operate, in-flight and on the ground, than today's more complex design approaches.

The "stack height," or total integrated space vehicle height, can be a real cost driver to launch system designs for a number of ground system processing stations and elements. For example, the total stack height drives assembly facilities, launch towers (both mobile and fixed), and launch pad structures (see Figure 3). Advanced development investments for innovative parallel tanks for cryogenic systems will give the designer more tank arrangement options to consider during conceptual design.

Tandem tank arrangements can also drive the concept towards slender dimensions with large overall length-todiameter (L/D) ratios. This leads to vehicle structural dynamic stability problems during flight. Additionally, tandem tank arrangement lengthens propellant feed line, protrudes the vehicle outer mold line (OML), and drives the engine start box thermal conditioning requirements; "pogo" affects, and added geyser protection systems. This in turn leads to added system design, production, and ground operations cost for stabilizers, dampeners, and so forth. Finally, tandem vehicle arrangements present issues of liftoff drift and launch tower re-contact.

Toroidal tank arrangements for space vehicles and stages can greatly improve the length-to-diameter (L/D) ratio, with far stronger inherent structural stiffness of the stage (as opposed to traditional tandem tank and tandemcommon bulkhead arrangements). This not only reduces the complexities of flexible-body stability and control dynamics of the vehicle in flight, it also improves the handling and access characteristics of the vehicle during ground operations. As with the common-bulkhead arrangement, it inherently avoids routine ground personnel access that can arise from the creation of an interstitial area between traditional, tandem tank arrangements (i.e., avoids creating an inter-tank compartment).

To date, the use of concentric-nested tanks for main propellant containment such as toroidal tank configurations tends to be avoided in the conceptual design processes. However, storable propellant applications are in production and operation using toroidal tanks in a number of Russian launch system designs, e.g., the Briz-M upper stage. The Sea Launch Zenit 3SL second and third stages also use toroidal kerosene fuel tanks with a LO2 propellant combination.

One drawback of a longitudinally-arranged inter-tank compartment is the temptation of locating functional hardware and ground interfaces within such a compartment. This immediately creates an opportunity for locating flight hardware functions requiring routine ground servicing at this location. Routine access by personnel may come in two forms: external access for mold-line connections/disconnections (which may have some potential for automation), but also internal access. Internal access requires added mass and complexity for entry hatches. However, if full personnel entry is required and not just a partial reach inside an opening, it will require the following:

- Time and effort to install and remove work platforms

- Establish lighting; establish oxygen/conditioned air flow for personnel to avoid confined space oxygen deficiency hazards

- Time and effort to install and remove various protective caps, covers and other remove-before-flight items strictly there to protect critical and delicate flight hardware from inadvertent damage 
- Ground-supplied purge systems to convert inert inter-tank atmosphere (gaseous nitrogen) to air for personnel entry and vice versa. These purge systems are active systems and are costly and timeconsuming to design and operate.

Another benefit of the toroidal tank arrangement is greater thermodynamic efficiency. Liquid hydrogen (LH2) has a lower boiling point value than liquid oxygen. Therefore, if the LO2 tank is the outer tank in a toroidal configuration, and a traditional cylindrical LH2 tank is nested inside, it can dramatically reduce hydrogen boil-off, as the outer LO2 tank acts as a more effective thermal radiation insulator than a traditional tank arrangement. This reduces the weight of vehicle thermal protection system (TPS) on the LH2 tank and could be especially beneficial in space or on an extraterrestrial surface.

For surface landing applications, the use of $\mathrm{LH} 2$ as a fuel for the propulsion function has been avoided because of boil-off during a medium stay time (say, a month). This boil off rate can be reduced by using concentric tank arrangements where the $\mathrm{LH} 2$ commodity is located on the interior, where its radiation heat barrier is the outer $\mathrm{LO} 2$ tank.

Another cryogenic use for this tank arrangement involves $\mathrm{LO} 2 / \mathrm{CH}_{4}$ propulsion; perhaps taking advantage of the availability of $\mathrm{CH} 4$ on Mars, for example. In this case, the boiling temperatures are very similar, offering a different set of design circumstances and considerations. Since liquid oxygen has a greater density than methane, it should be the outer tank and an integral part of the structure, and carry the load of the stage or vehicle.

A commonly-raised issue to be addressed is that the inner cylindrical wall of an elongated toroidal tank will be in radial compression when pressurized. Typically, the cylindrical wall of a pressure vessel is mostly in tension. Being primarily in compression, the inner cylindrical wall must be designed for high strength. However, the mass and strength required of such a wall, as part of the pressure vessel, can also double as the means of carrying the majority of vehicle's weight and thrust loads. The architectural implications are quite profound if the life cycle costs and ownership benefits are fully considered. The payoff may be well worth the investment to explore innovations that overcome the perceived difficulties.

A promising configuration to be explored uses a traditional cylindrical cryogenic tank inside another concentric toroidal cryogenic tank. The two parallel "nested" tanks are separated by compliant filler material as the two cryogenic tanks expand and contract between ambient and cryogenic temperatures. A common barrel section (similar to common bulkhead arrangements) to reduce weight is not what is envisioned. This is primarily due to operational safety considerations, along with the production and propellant loading/offloading complexities of a common structural face encountering two different cryogenic fluids, each having unique thermal transport properties. Also, in this configuration, the outer propellant tank as an integral structure to the vehicle while the interior tank (either cylindrical or toroidal) is a non-load bearing structure. Whether the interior hydrogen tank is toroidal or a standard cylindrical design depends on the application. The LO2 tank interior wall should carry the longitudinal load of the vehicle. If so, the interior hydrogen tank can be a very lightweight, traditional cylindrical tank with standard end domes. If, however, the interior tank is also toroidal, a crew access airlock can be inserted in the interior space created in a spacecraft application.

The concentric-nested tank arrangement, unlike the common-bulkhead, with compliant insulation in the expanding and contracting interstitial volume between the tanks allows free flow of the upper inter-tank compartment's purge gas to flow into the aft compartment. This arrangement deletes one of the traditional tank design's ground-supplied compartment purges. In addition, the procedural constraints required of the common bulkhead dome (sometimes called the "crotch" area) during cryogenic loading because of major stresses in the face sheets are eliminated. These issues are avoided in the concentric tank approach. Production complexities with use of a common bulkhead are likewise avoided, but not addressed here. The insulation between the interior and exterior tanks needs to be compliant and allow for expansion and contraction with changes in the tank diameters.

\section{B. LO2-Rich/LO2-Cooled First Stage Earth-to-Orbit (ETO) Main Engine}

This proposed technology uses large-scale thrust cryogenic engines (say 1- to 2 million-pound thrust class) with an oxidizer-rich (LO2-rich), rather than the traditional fuel-rich (LH2-rich) main combustion mixture ratio. A promising approach would have the mixture ratio set at $\sim 12: 1$ at liftoff and reduced during ascent. This technology would then allow a much higher propellant bulk density for the first stage propellant tanks or a greatly increased mass fraction over traditional configurations.

As with concentric-nested tanks, this technology allows a far more compact vehicle structure. It does so by the reduction of the volume requirement of the hydrogen tank substantially more than the increased oxygen tank volume required to supply the oxygen-rich engine (due to the relative densities of the propellants). It also results in a far simpler cryogenic propulsion system to operate in-flight and on the ground than today's more complex design approaches. This approach will achieve the required thrust at liftoff with fewer main engines and will decrease the 
safety risk at ignition or with an abort shutdown at the launch pad. The ignition overpressure will also be eliminated deleting the need for the ground system hydrogen burn-off system at liftoff.

1. Engine Combustion Mixture Ratio (MR) Considerations

In the Space Shuttle Main Engine (SSME) and the Delta IV's RS-68 applications, the ratio of the oxygen mass to the liquid hydrogen mass is six-to-one (6:1). The stoichiometric ratio of burning hydrogen and oxygen to produce water (i.e., neither fuel-rich nor oxidizer- rich) is $8: 1$, by mass. The hydrogen-rich $6: 1$ ratio drives the design to a large vehicle hydrogen tank volume.

If the mixture ratio is 12:1 (i.e., LO2-rich) for first stage operation in the atmosphere, then the size of the main fuel tank, and thus the total dry mass fraction of the vehicle, is substantially increased. There is a specific impulse $\left(I_{s p}\right)$ reduction to the traditional $6: 1 \mathrm{M} / \mathrm{R}$, but still results in an overall smaller vehicle combined tank volume and the engine $I_{s p}$ value is still larger than any other propellant choice for first stage operation.

2. Engine (Combustion Chamber) Cooling Considerations during Combustion

Since LO2 cooling feasibility testing has been demonstrated for both LO2/LH2 and LO2/RP-1 engines by NASA's Lewis Research Center (now Glenn Research Center, GRC), it is proposed to cool the combustion chamber with LO2. Cooling propellant is required to be present for both the lead and lag for start of the engine and its shutdown, and will increase safety of launch operations by eliminating the excess free hydrogen both at start-up and during shutdown. This condition of gaseous hydrogen lead during engine start and shutdown is much more severe with the RS- 68 rocket engine and would be considered a safety risk with a crewed vehicle.

Liquid oxygen should be more advantageous and may be needed as the heat flux of the much higher mass flow (higher thrust) engine is much greater than the traditional 6:1 mixture ratio (MR) LO2/LH2 engine.

\section{Combined, High Payoff Benefit}

When combined with the concentric-nested tank design approach, the design space for earth-to-orbit launch systems opens up new and innovative configurations; ones that can offer far more utility, efficiency, and value to the owner-operator. Specifically, a configuration based on these design approaches, and using these high payoff technologies, will allow elimination of long engine feed lines and active engine conditioning systems. Without a concerted effort to remove these complexities, support systems will continue to accumulate in designs presently caused by conditioning requirements for starting the engine. It also allows the designer freedom to eliminate $\mathrm{LO} 2$ "pogo" suppression systems, elevated ground servicing fill and drain systems, additional compartment conditioning, and hazardous gas leak detection systems. For example, a trade study using the Delta IV five (5) meter diameter first stage shows a combined benefit can be achieved, reducing the first stage vehicle length by as much as $50 \%$.

\section{Non-Toxic, Day-of-Launch-Loaded Propellants (LO2/CH4, or LO2/LH2, for example)}

This technology enables the spacecraft main and auxiliary propellants to be loaded on the day of launch. On a small scale, this was accomplished for the DC-X vehicle (see Figure 2). Advancements and investments can bring this design technique to full-scale and bring about many affordable system attributes described below.

Specification of traditional toxic hypergolic bi-propellants has led to complex and time-consuming operations that are an impediment to the owner-operator since they drive up both recurring production and ground operations costs. Impediments to efficient and affordable ground operations are: personnel protection suit infrastructure; added manual propellant operation time; and serial loading operations requiring "stop work" on all other vehicle systems adding critical path operations (often on the order of weeks) for propellant loading and system pressurization operations. Separate auxiliary propulsion servicing, even when automated and performed remotely, adds a considerable expense to the design, fabrication and maintenance functions of the space transportation system. Additionally, if a toxic fluid is selected, added offline facilities that require special toxic commodity facility systems may be required, adding a substantial cost burden to the transportation system.

Using LO2-Methane engine technology provides affordability and performance advantages that avoid these ground operations impediments. Weeks are often found in the critical path for a hypergolic propellant loading procedure at the launch pad. Alternatively, an entire launch site processing station dedicated to the hypergolic fuelloading function can be designed, constructed, maintained, and operated offline from the rest of the vehicle operations, but with significant added cost. A dedicated processing station not only creates a separate, dedicated spacecraft hazardous processing facility and its operations, but also requires: associated hazardous and nonhazardous facility systems; a great deal of complex, dedicated hazardous and non-hazardous fluid servicing equipment; and dedicated handling and access equipment, stands, etc. The choice of avoiding non-toxic propellants (such as LO2-Methane and $\mathrm{LO} 2 / \mathrm{H} 2$ propellant, which could be loaded during the final countdown) also causes the added burden of dedicated hypergolic SCAPE operations and maintenance activity. Offline facility stations of this complexity often consider separate dedicated ground operations control rooms and facility systems to manage containment of emergency fluid spills, toxic vapor control, waste management systems, and offline operations. 
These added systems for facility safety mitigation involve complex scrubbers, underground containment, exhaust systems, requirement for extremely tall major facility pipes and vents, and so forth.

Use of non-toxic propellant combinations also eliminates the operations and maintenance (O\&M) for the dedicated hazardous facility, specialized GSE, and the fixed and mobile support equipment such as mobile SCAPE vans, SCAPE maintenance facilities, and personnel that support the SCAPE technicians and their suits. Further, it eliminates the added waste management function and its burden and the logistics cost of the unique hypergolic bipropellants. Other than the Long March system of launch vehicles, very few, if any, modern launch systems use hypergolic propellants in large quantities anymore. Finally, personnel health monitoring, safety training overhead, record-keeping burden, and health industry personnel support to the SCAPE technicians are required.

All of these attributes and characteristics of toxic systems add a significant burden to the design of flight and ground systems, their recurring manufacture, production and supply, as well as ground operations work and time burden.

\section{Electric Propulsion/Thrust Vector Control System (Electro-mechanical, self-contained Electro-hydrastatic actuators, EMAs/EHAs)}

Propellant control valves and thrust vector control (TVC) systems often use a small quantity of toxic hydrazine and distributed high-pressure (3,000 psi) hydraulics to gimbal the nozzle for ascent flight control. Alternatives to toxic hydrazine is the use of a main propulsion gas to drive a high speed turbine, combined with high pressure distributed hydraulics, as well as high voltage electrical subsystem to actuate the engine for ascent flight control. A much simpler technology approach exists to avoid the extra cost, complexity, and operations of employing and collecting all these technologies for a simple thrust vector control task. The use of electromechanical actuators (EMAs) and electro-hydrostatic actuators (EHAs) eliminates the need for distributed hydraulics or distributed pneumatic systems for backup. This enabling technology would considerably reduce the amount of ground support systems; equipment and procedures; remanufacturing purchases; disassembly, refurbishment, and re-assembly work; and the required personnel workforce to accomplish the support of the extra subsystems, e.g., hydrazine, hi-pressure hydraulics, and pneumatic systems.

More specifically, use of all-electric approaches in recoverable systems that subsequently require remanufacturing would eliminate the need for any dedicated test facilities needed to protect personnel during system testing prior to element assembly. It would also eliminate numerous fluid and pneumatic GSE and facility systems requirements. It would simplify recurring production costs. It also streamlines the pad propellant loading operations prior to launch countdown as well as the procurement and use control of these additional fluid commodities. The hazards and expense of pad-clear loading operations and use of the SCAPE infrastructure can be avoided by using non-toxic propellants and electric, TVC. It also eliminates the use of distributed hydraulic systems that require considerable launch site equipment, GSE, and labor to maintain and operate. To gain this benefit, the development of non-toxic propellants EMA/EHA TVC for high-thrust engines must be matured and implemented in the design process together.

All of this would reduce design and recurring production cost, ground operations and ground support equipment (and in the hydrazine case, some dedicated hazardous facilities and rooms), and operations work content and serial critical time to produce a space flight.

\section{Conclusions and Recommendations}

Investing in and implementing the essential technologies presented, and using the six-step process suggested in this paper, would have a positive impact on major contributors to life cycle cost: (1) work effort and time involved with the design development, testing and evaluation phase; (2) the recurring production and vendor supply in sustaining the system by design; (3) flight and ground operations work accumulation by design, and (4) overall launch productivity improvement through major reduction in the critical path time necessary to produce a space flight. The six-step approach and the suggested technologies and advanced design techniques represent a very high payoff design approach that would enable an affordable and sustainable space transportation system. 
Table 1. Criteria correlations with various components of life cycle affordability.

\begin{tabular}{|c|c|c|c|c|c|c|c|c|c|}
\hline AFFORDABILTY CRITERIA & 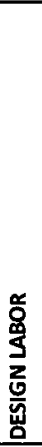 & 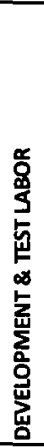 & 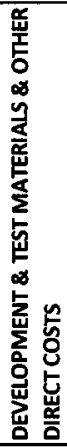 & 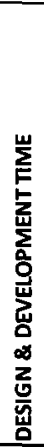 & 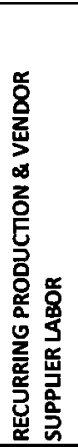 & 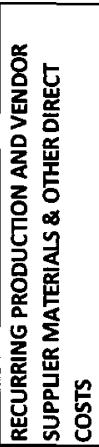 & 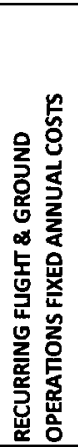 & 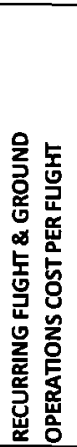 & 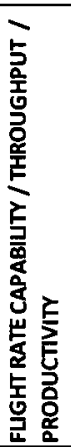 \\
\hline Percentage of elements and systems that are highly reusable & & & & & $\mathrm{x}$ & $\mathrm{x}$ & $x$ & $\mathrm{x}$ & $\mathrm{x}$ \\
\hline Total number of flight tanks in the architecture & $\mathrm{x}$ & $\mathrm{x}$ & $\mathrm{x}$ & $\mathrm{x}$ & $\mathrm{x}$ & $\mathrm{x}$ & $\mathrm{x}$ & $\mathrm{x}$ & $x$ \\
\hline Total number of separate identıfied vehicle propulsıon systems & $x$ & $x$ & $x$ & $x$ & $x$ & $x$ & $x$ & $x$ & $x$ \\
\hline Number of safety driven functional requirements to maintain safe & & $x$ & $x$ & $x$ & $x$ & $x$ & $x$ & $x$ & $x$ \\
\hline $\begin{array}{l}\text { control of systems during flight and ground operations } \\
\text { Number of maintenance actions unplanned before or between }\end{array}$ & $Y$ & & & $\hat{n}$ & & n & & & \\
\hline missions & $x$ & X & $x$ & $x$ & $x$ & $x$ & $\mathrm{x}$ & X & $\mathrm{x}$ \\
\hline Number of maintenance actions planned before or between missions & & & & & $\mathrm{x}$ & $\mathrm{x}$ & $\mathrm{x}$ & $\mathrm{x}$ & $\mathrm{x}$ \\
\hline Total number of traditional ground interface functions required & $\mathrm{x}$ & $\mathrm{x}$ & $\mathrm{x}$ & $\mathrm{x}$ & $\mathrm{x}$ & $\mathrm{x}$ & $\mathrm{x}$ & $\mathrm{x}$ & $\mathrm{x}$ \\
\hline Percent of all systems not automated & & & & & $\mathrm{x}$ & $\mathrm{x}$ & $\mathrm{x}$ & $\mathrm{x}$ & $x$ \\
\hline Number of different fluids required & $\mathrm{x}$ & $x$ & $x$ & $\mathrm{x}$ & $x$ & $\mathrm{x}$ & $\mathrm{x}$ & $\mathrm{x}$ & $\mathrm{x}$ \\
\hline Total number of vehıcle element-to-element support systems & $x$ & $\mathrm{x}$ & $x$ & $\mathrm{x}$ & $\mathrm{x}$ & $\mathrm{x}$ & $x$ & $\mathrm{x}$ & $\mathrm{x}$ \\
\hline Number of flight vehicle serviang interfaces & $x$ & $x$ & $x$ & $\mathrm{x}$ & $x$ & $\mathrm{x}$ & $x$ & $\mathrm{x}$ & $\mathrm{x}$ \\
\hline Number of confined/closed compartments & $\mathrm{x}$ & $x$ & $x$ & $\mathrm{x}$ & $x$ & $\mathrm{x}$ & $\mathrm{x}$ & $\mathrm{x}$ & $\mathrm{x}$ \\
\hline $\begin{array}{r}\text { Number of commodities used that require medical support } \\
\text { operations and routine tranıng }\end{array}$ & & $\mathrm{x}$ & & $\mathrm{x}$ & $x$ & $\mathrm{x}$ & $\mathrm{x}$ & $\mathrm{x}$ & $x$ \\
\hline Number of safety driven limited access control operations & & $\mathrm{x}$ & $x$ & $x$ & & & $x$ & $x$ & $x$ \\
\hline Number of safing operations at landing (for reusable elements) & $x$ & $x$ & $x$ & $x$ & $x$ & $\mathrm{x}$ & $x$ & $\mathrm{x}$ & $x$ \\
\hline Number of mechanical element mating operations & & $\mathrm{x}$ & $\mathrm{x}$ & $\mathrm{x}$ & & & $x$ & $\mathrm{x}$ & $\mathrm{x}$ \\
\hline Number of separate electrical supply interfaces & $\mathrm{x}$ & $\mathrm{x}$ & $x$ & $\mathrm{x}$ & $x$ & $\mathrm{x}$ & $\mathrm{x}$ & $\mathrm{x}$ & $\mathrm{x}$ \\
\hline Number of intrusive data gathering devices & & $\mathrm{x}$ & $x$ & $\mathrm{x}$ & $x$ & $\mathrm{x}$ & $x$ & $\mathrm{x}$ & $x$ \\
\hline Number of Criticality 1 system and fallure analysis modes & $x$ & $x$ & $x$ & $x$ & $x$ & $\mathrm{x}$ & $\mathrm{x}$ & $\mathrm{x}$ & $\mathrm{x}$ \\
\hline
\end{tabular}




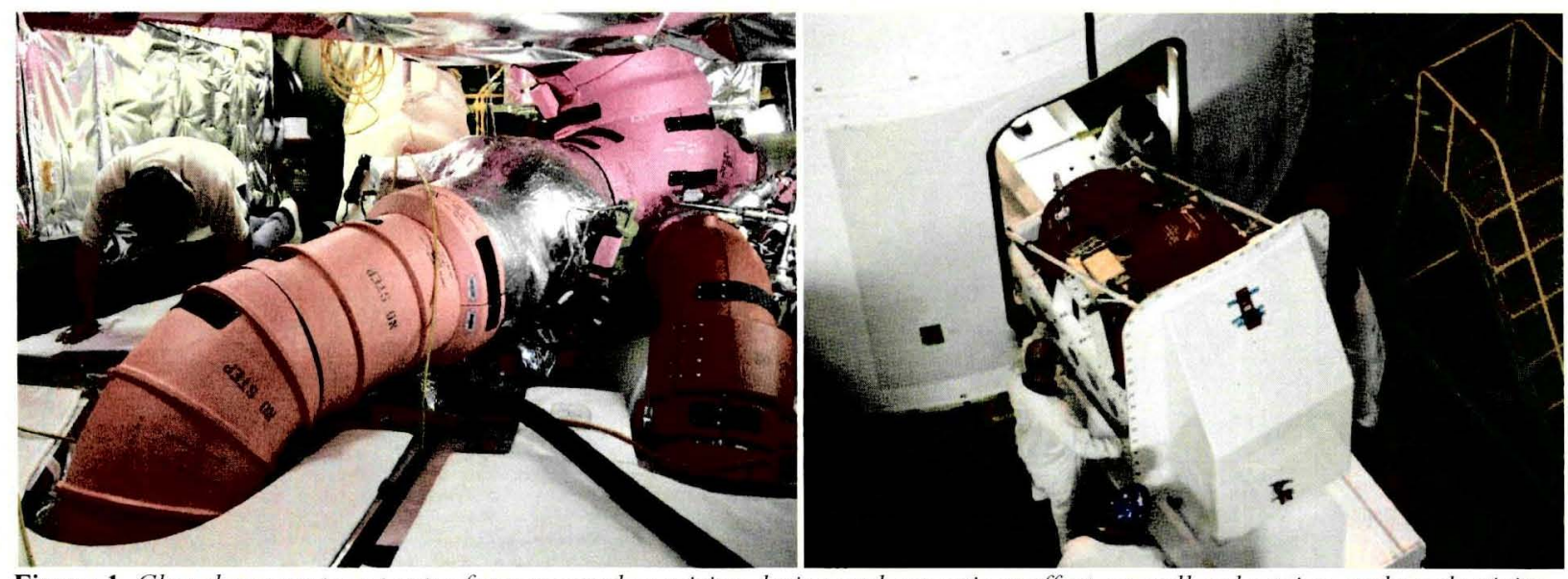

Figure 1. Closed compartment entry for personnel requiring design and operations effort, as well as lost time and productivity.
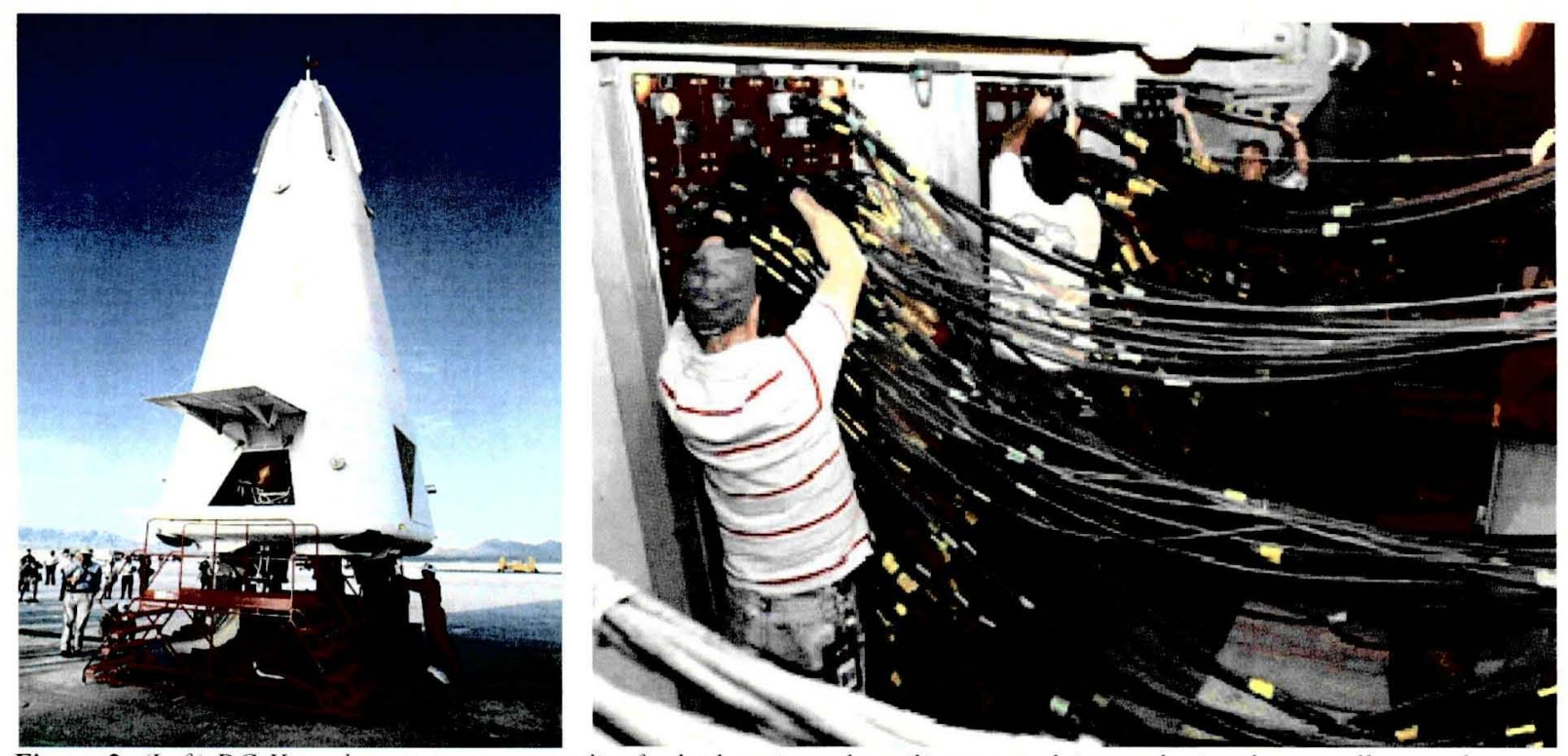

Figure 2. (Left) DC-X used a common commodity for both main and auxiliary propulsion, reducing the overall ground operations work involved had a dedicated commodity been used. (Right) a high degree of dedicated, specialized power and signal requirements can be seen for a large-scale mobile launch system. Greater design integration can reduce design, development, fabrication, testing, and ground operations. 

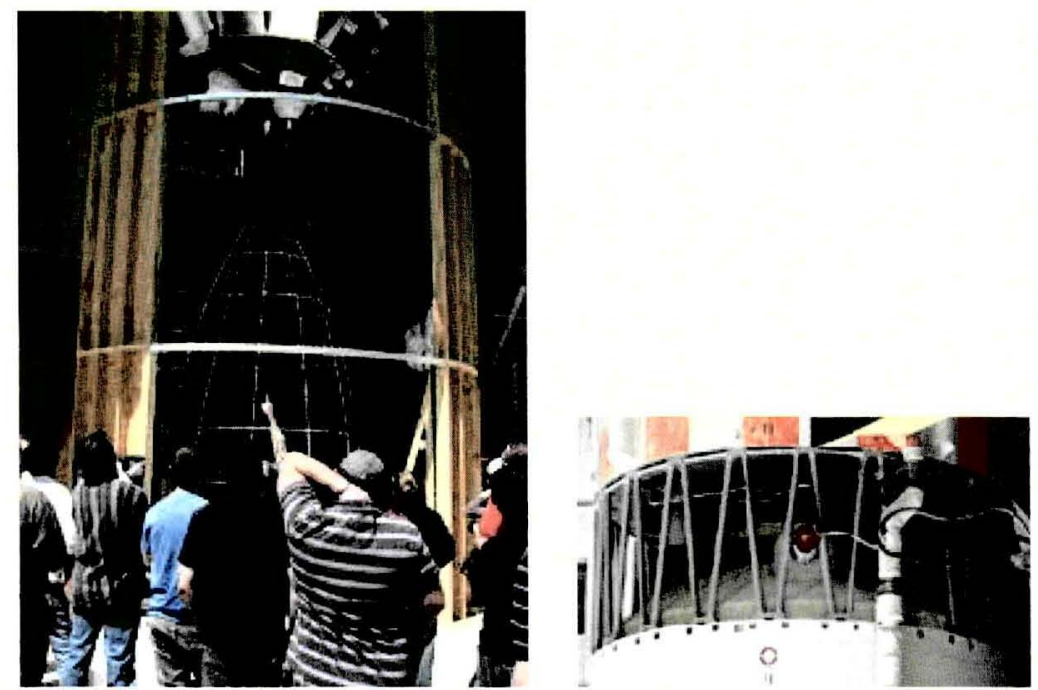

Figure 3. Photo on left shows typical inter-stage design mock-up requiring routine internal personnel access (left). The photo on the right shows the Zenit SeaLaunch interstage, including the upper stage engine nozzle, encapsulated within a concentric-nested stage design (described in Step 2, item 4). None of the following are required: routine personnel entry; environmental control system (ECS); personnel work platform installation and removals; installation of lighting and oxygen deficiency monitoring equipment; and compartment closeout work, including hatch removal, installation, sealing, and thermal protection. The difference in stack height. and implied mass savings also are apparent. Also note the propellant feed-line extending from the lower stage, through the inter-stage and into the upper stage for fill and drain. This eliminates the need for side-mounted service umbilicals and large service towers to support them.

\section{Total Propellant Volume Comparison relative to $M R=6$}

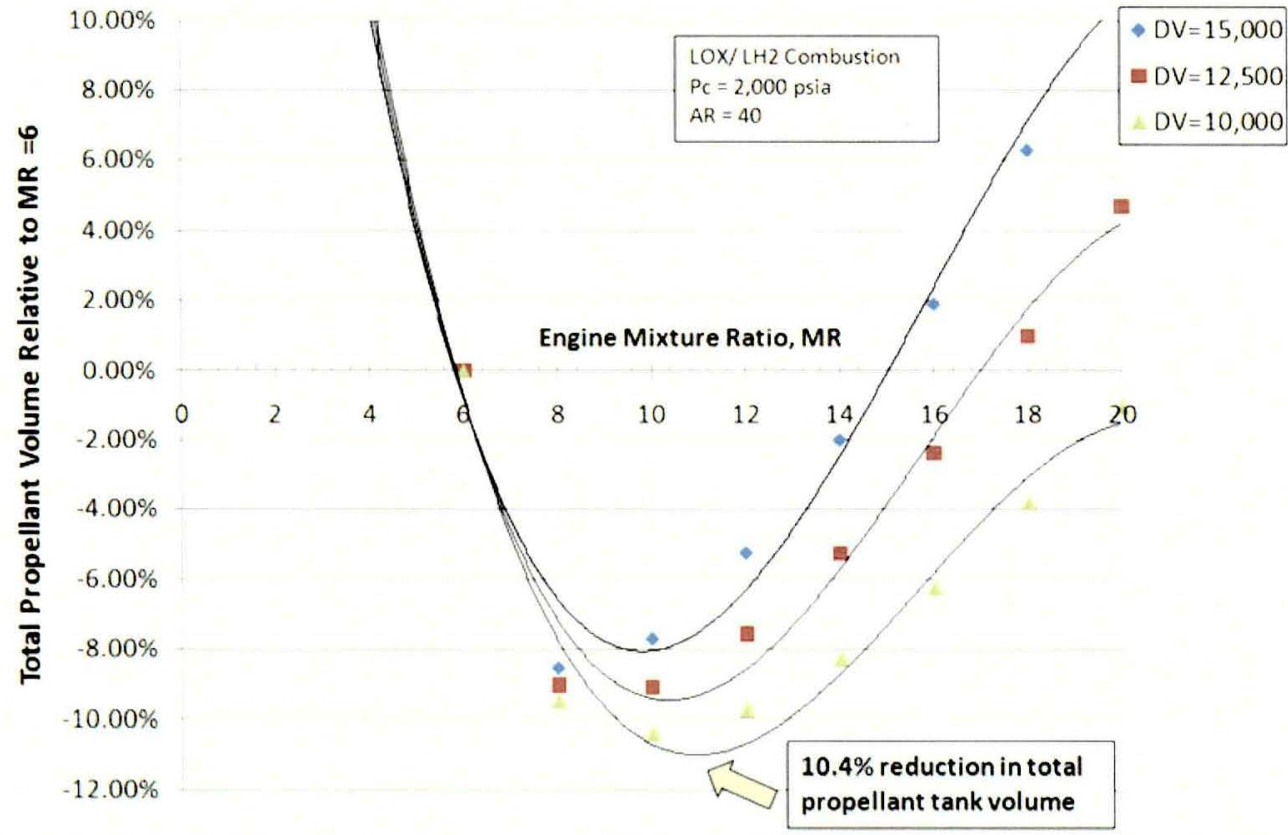

Figure 4. Vehicle Propellant Tank Volume Reduction with LO2-Rich Combustion Engine.

American Institute of Aeronautics and Astronautics 


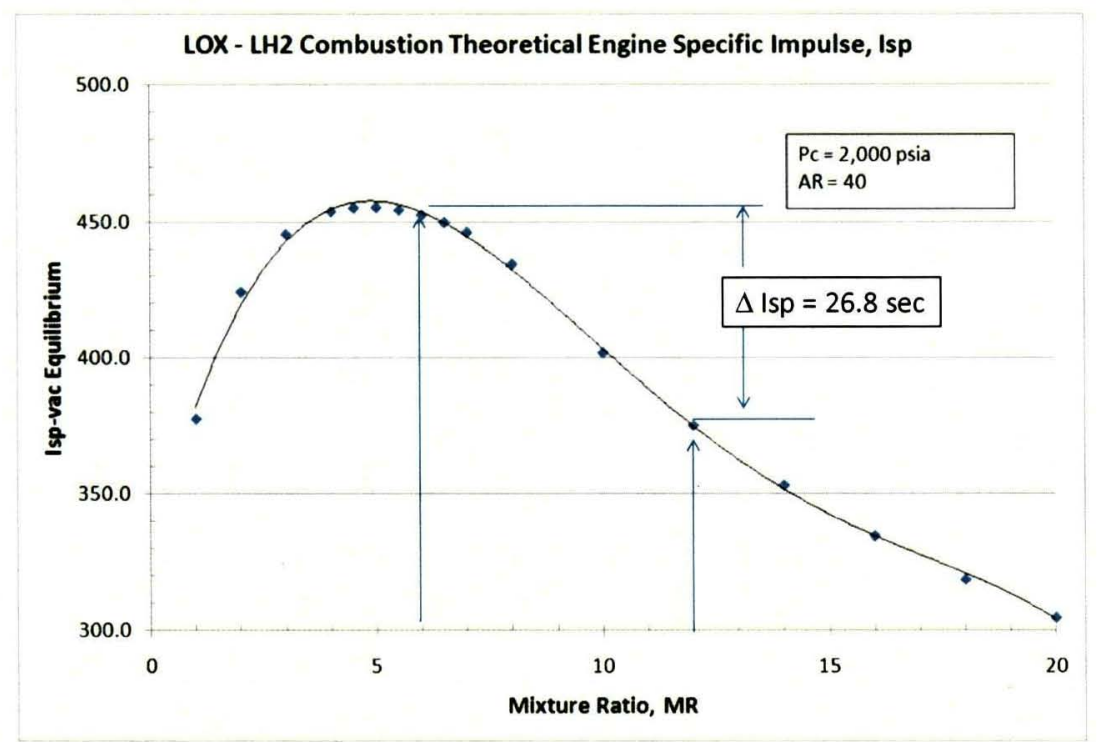

Figure 5. Theoretical Engine Specific Impulse for LO2-LH2 Combustion.

\begin{tabular}{l|c|r|} 
Total Tank volume $=$ & $\mathrm{ft}^{\wedge} 3$ & $20,510.38$ \\
Fuel tank volume $=$ & $\mathrm{f}^{\wedge} 3$ & $15,002.90$ \\
Oxid tank volume $=$ & $\mathrm{ft}^{\wedge} 3$ & 5.507 .48 \\
d1, Tank diameter & $\mathrm{m}$ & 3.80 \\
Tank diameter & $\mathrm{t}$ & 12.47 \\
Tank diameter & in. & 149.61 \\
A1. Cylindrical cross-sect area & $\mathrm{ft}^{\wedge} 2$ & 488.30 \\
Equiv cylindrical length, $\mathrm{h}=$ & $\mathrm{ft}$ & 30.72 \\
A-tot. Cylindrical cross-sect ar & $\mathrm{ft}^{\wedge} 2$ & 667.55 \\
d2 = & $\mathrm{ft}$ & 29.15 \\
d2, Outer tank diameter $=$ & $\mathrm{m}$ & 8.89
\end{tabular}

note:

1) CBC baseline tank diameter is 5 meter

2) $\%$ tank length from vertical stack

Figure 6. Delta IV Medium Common Booster Core (CBC) nested tank calculation for baseline configuration.

\begin{tabular}{|c|c|c|c|c|}
\hline Total Tank volume $=$ & $\mathrm{ft}^{\wedge} 3$ & 18.435 .5 & $89.88 \%$ & note 1 \\
\hline Fuel tank volume $=$ & $\pi^{\wedge} 3$ & $10,672.74$ & & \\
\hline Oxid tank volume $=$ & $\pi^{n} 3$ & 7.762 .76 & & \\
\hline d1, Tank diameter & $\mathrm{m}$ & 3.80 & & note 2 \\
\hline Tank diameter & $\mathrm{ft}$ & 12.47 & & \\
\hline Tank diameter & in. & 149.61 & & \\
\hline A1. Cylindrical cross-sect area & $t^{\wedge} 2$ & 488.30 & & \\
\hline Equiv cylindrical length, $\mathrm{h}=$ & A & 21.86 & $50.35 \%$ & note 3 \\
\hline A-tot, Cylindrical cross-sect area & $A^{\wedge} 2$ & 843.46 & & \\
\hline $\mathrm{d} 2=$ & $\mathrm{ft}$ & 32.77 & & \\
\hline d2, Outer tank diameter = & $\mathrm{m}$ & 9.99 & & \\
\hline \multicolumn{5}{|l|}{ note: } \\
\hline \multicolumn{5}{|l|}{ 1) \% trom MR = 6 total tank volume } \\
\hline \multicolumn{5}{|c|}{ 2) CBC baseline tank diameter is 5 meter } \\
\hline
\end{tabular}

Figure 7. Delta IV Medium Common Booster Core (CBC) nested tank calculation for LO2-rich configuration.

American Institute of Aeronautics and Astronautics 


\section{NOTES}

${ }^{1}$ Space Propulsion Synergy Team (SPST) web site: http://spacepropulsion.us [link available as of June 23, 2011 ].

${ }^{2}$ Rhodes, R. E., Zapata, E., Levack, D. J. H., Robinson, J. W., and Donahue, B. B., members Space Propulsion Synergy Team (SPST), "Concepts for Life Cycle Cost Control Required to Achieve Space Transportation Affordability and Sustainability," AIAA 2009-5345, 45th AIAA/ASME/SAE/ASEE Joint Propulsion Conference, Denver, Colorado, 2-5 August 2009.

3 DeHoff, B., Levack, D. J. H., and Rhodes, R. E., members Space Propulsion Synergy Team (SPST), "The Functional Breakdown Structure (FBS) and Its Relationship to Life Cycle Cost," AIAA 2009-5344, 45th AIAA/ASME/SAE/ASEE Joint Propulsion Conference, Denver, Colorado, 2-5 August 2009. 


\section{High-Payoff Space Transportation Design Approach with a Technology Integration Strategy}

C. M. McCleskey \& R. E. Rhodes NASA Kennedy Space Center, Florida

T.T. Chen

NASA Marshall Space Flight Center, Huntsville, Alabama J.W. Robinson

The Boeing Company (ret.), Huntington Beach, California

\section{Presented}

August 1, 2011

at the

$47^{\text {th }}$ AIAA/ASME/SAE/ASEE Joint Propulsion Conference \& Exhibit

San Diego, California 


\section{Six Critical Steps to an Affordable, Economically Sustainable System Design}

1. Simplify the vehicle/ground system architecture

2. Efficiently package each vehicle element's propulsion system (i.e., tank, engine and compartment layouts)

3. Integrate vehicle element functions into the lowest number of subsystems/components with minimum ground support requirements

4. Integrate ground element functions into the lowest number of work stations, facilities, and support equipment

5. Simplify avionics and flight control design into minimum components; then, power and automate what's left

6. Extensively flight test to demonstrate accomplishment of all production and operations needs and objectives for full operational system capability with the affordability objective met 


\section{Step One Simplify the Vehicle Architecture}

1. Simplify the vehicle/ground system architecture

2. Efficiently package each vehicle element's propulsion system (i.e., tank, engine and compartment layouts)

3. Integrate vehicle element functions into the lowest number of subsystems/components with minimum ground support requirements

4. Integrate ground element functions into the lowest number of work stations, facilities, and support equipment

5. Simplify avionics and flight control design into minimum components; then, power and automate what's left

6. Extensively flight test to demonstrate accomplishment of all production and operations needs and objectives for full operational system capability with the affordability objective met 


\section{Step Two \\ Efficiently Package Each Propulsion System}

1. Use minimum number of main and auxiliary propellant commodities, (e.g., day-of-launch-loaded LOX/LH2 only)

2. Keep ground interface connections close to ground level to avoid a series of elevated, articulating umbilicalsparticularly, lift-off umbilicals

3. Avoid complexities of common-bulkhead, tandem tank arrangements and separate auxiliary propulsion systems

4. Use a minimum number of main engines with a minimum amount of turbo-machinery and interconnecting main propulsion system plumbing 


\section{Integrate Functions into the Lowest Number of Subsystems/Components}

- $\quad$ Create generic functional systems breakdown structure for each element

- Combine (or integrate) as many functions into singular systems

- Provide a minimum of standalone, dedicated subsystems

- Minimizes accumulated subsystems, components, and interfaces

- Combine propulsion \& power functions with common propellants/commodities to avoid separate fill and drain, storage and distribution subsystems, ground interfaces, and GSE

- Use technical approaches that inherently require fewer separate support subsystems to perform the function (e.g., EMA/EHAs)

- $\quad$ Cumulative DDT\& E effort is greatly reduced (flight \& ground systems)

- Recurring production effort

- Number of separate suppliers required to sustain the system

- Recurring ground operations work:

- Processing times are reduced

- Recurring labor, materials, and other direct costs 


\section{Step Four \\ Integrate ground functions into the lowest number of facilities and equipment}

Ten (10) items specified in paper. Examples include:

- Objective is to first minimize requirements for interfaces

- Then, eliminate requirements for elevated umbilicals...locate near ground level

- For reusable systems, design vehicle for phased maintenance (several specifics identified)

- Utility and productivity of facility assets should be considered

- Spectrum of reusability greatly affects required facility \& equipment infrastructure across the enterprise:

- Salvage and Reuse

- Expendable

- Moderately Reusable

- Reusable

- Highly Reusable

- Avoid toxics, ordnance, etc. that drive dedicated facilities 


\section{Simplify avionics and flight control design using}

\section{minimum components... power \& automate what's left}

- Use simple, dependable flight control mechanisms that do not require routine fluid and/or gas servicing during ground operations

- Keep number of dedicated avionics boxes to an absolute minimum to the point where no dedicated active avionics cooling subsystems are required

- Build-in enough mass margins to account for avionics cable lengths and interconnectivity hardware

- Avoid specialized ground power

- Build in remote autonomous avionics functional verification every time systems are powered-up 


\section{Extensively Test/Adjust the Design to Qualify the System and Achieve the Objectives}

- Prove-out design assumptions of simplicity

- Build technical and managerial confidence in a simple, robust system prior to committing to production

- Allow flight test program to schedule improvements in system design prior to committing to production

- Maintain a separate, developmental component, subsystem, system, and flight test infrastructure and capability

- Offline from operational transportation service to continually work in improvements

- Take flight risk of new improvements off-line from operational systems

- Progress in affordability should allow less expensive flight testing

- Creates technology maturation capability (beyond TRL 6) needed by our space transportation industry 


\section{Four Essential Technologies Concentric-Nested Propellant Tanks}

- Advanced development work could greatly simplify architectural design

- Configuration locates outer toroidal tank to take vehicle and engine thrust loads (e.g, LOX outer/LH2 inner)

- Inner wall of the external of the two tanks is integral to structure of space vehicle for cryogenic application

- Enables overall vehicle architecture to achieve a far more compact vehicle structure whose cryogenic propulsion system is far simpler to operate, in-flight and on the ground, than traditional complex design approaches

- Eliminates operations, weight penalties, and improves inherent reliability through elimination of support systems (ECS, pogo-suppression, anti-geysering, resulting ground services, etc.)

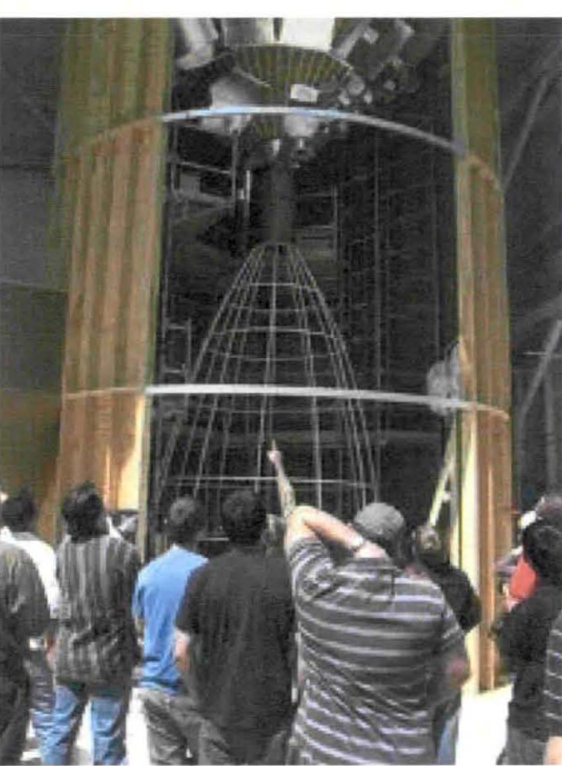

Closed compartment Interstage design

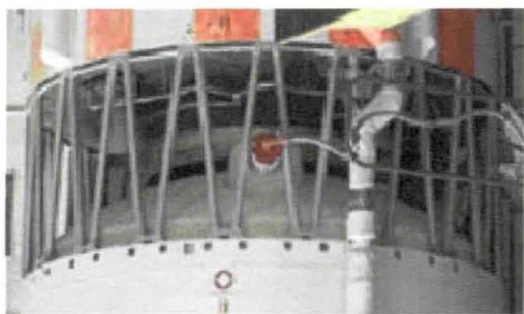

Open compartment interstage design with concentric -nested upper stage

- Allows ground access for propulsion system servicing 


\section{Four Essential Technologies LO2-Rich/LO2-Cooled First Stage Earth-to-Orbit (ETO) Main Engine}

- Advanced concept would use large-scale thrust cryogenic engines (say 1- 2 million-pound thrust class) with LO2-rich main combustion mixture ratio (MR)

- Promising approach would have mixture ratio set at $\sim 12: 1$ at liftoff and reduced during ascent

- Allows higher propellant bulk density for the first stage propellant tanks, or, greatly increased mass fraction

- Allows far more compact vehicle structure

- Reduction of volume requirement of LH2 tank substantially more than increased LO2 tank volume required to supply LO2-rich engine (due to the relative densities of the propellants)

- Results in simpler cryogenic propulsion system to operate in-flight \& ground than today's approaches

- Achieves required thrust at liftoff with fewer main engines and decreases safety risk at ignition or with an abort shutdown at the launch pad

- LO2-cooling eliminates ignition overpressure by deleting need for ground system hydrogen burn-off system at liftoff (LO2 lead/lag more benign than LH2)

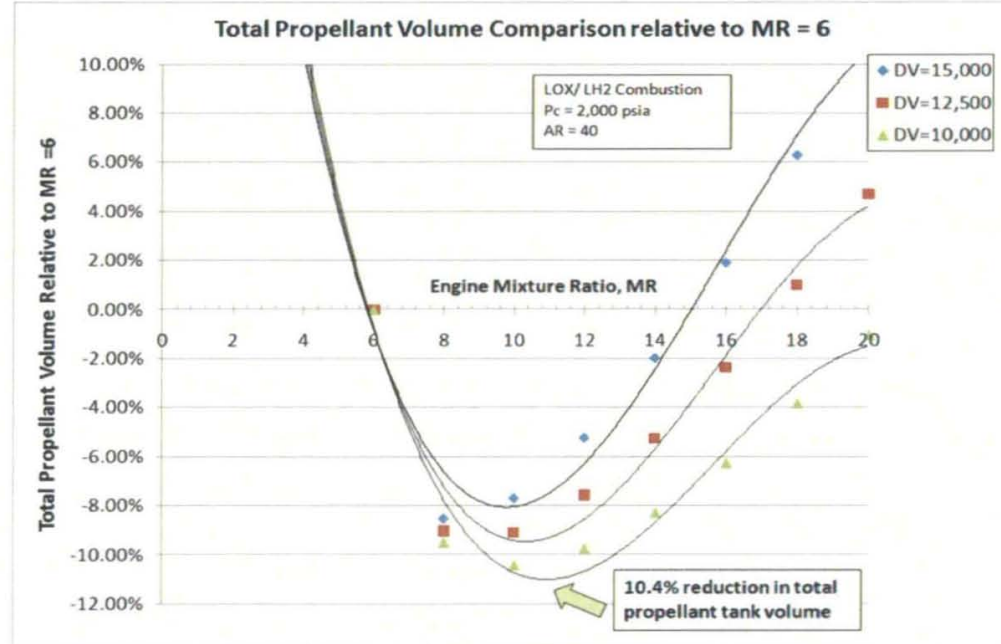

LOX - LH2 Combustion Theoretical Engine Specific Impulse, Isp 500.0

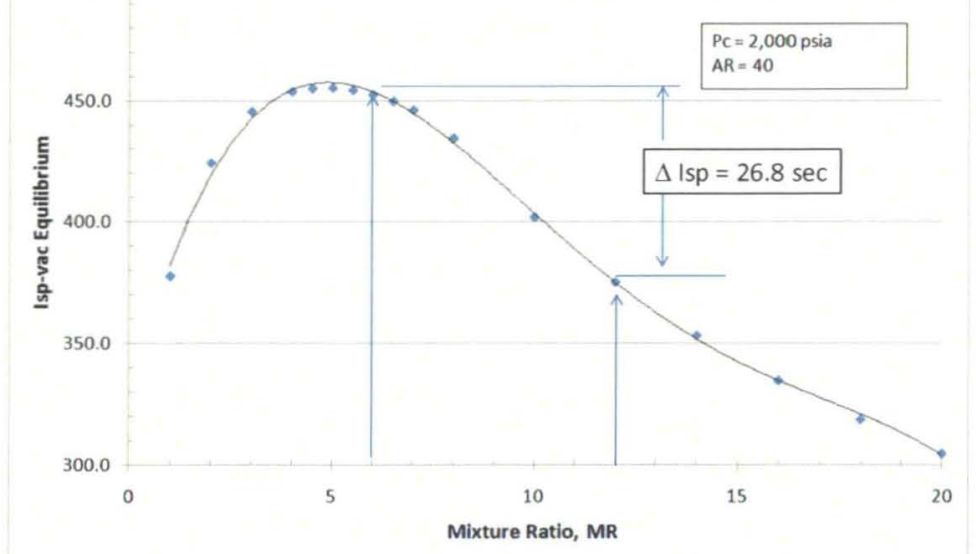




\section{Four Essential Technologies Other examples}

- Avoid expensive toxic auxiliary propulsion issues

- Hydrazine/Hydraulic vs. Electric thrust vector control (TVC)
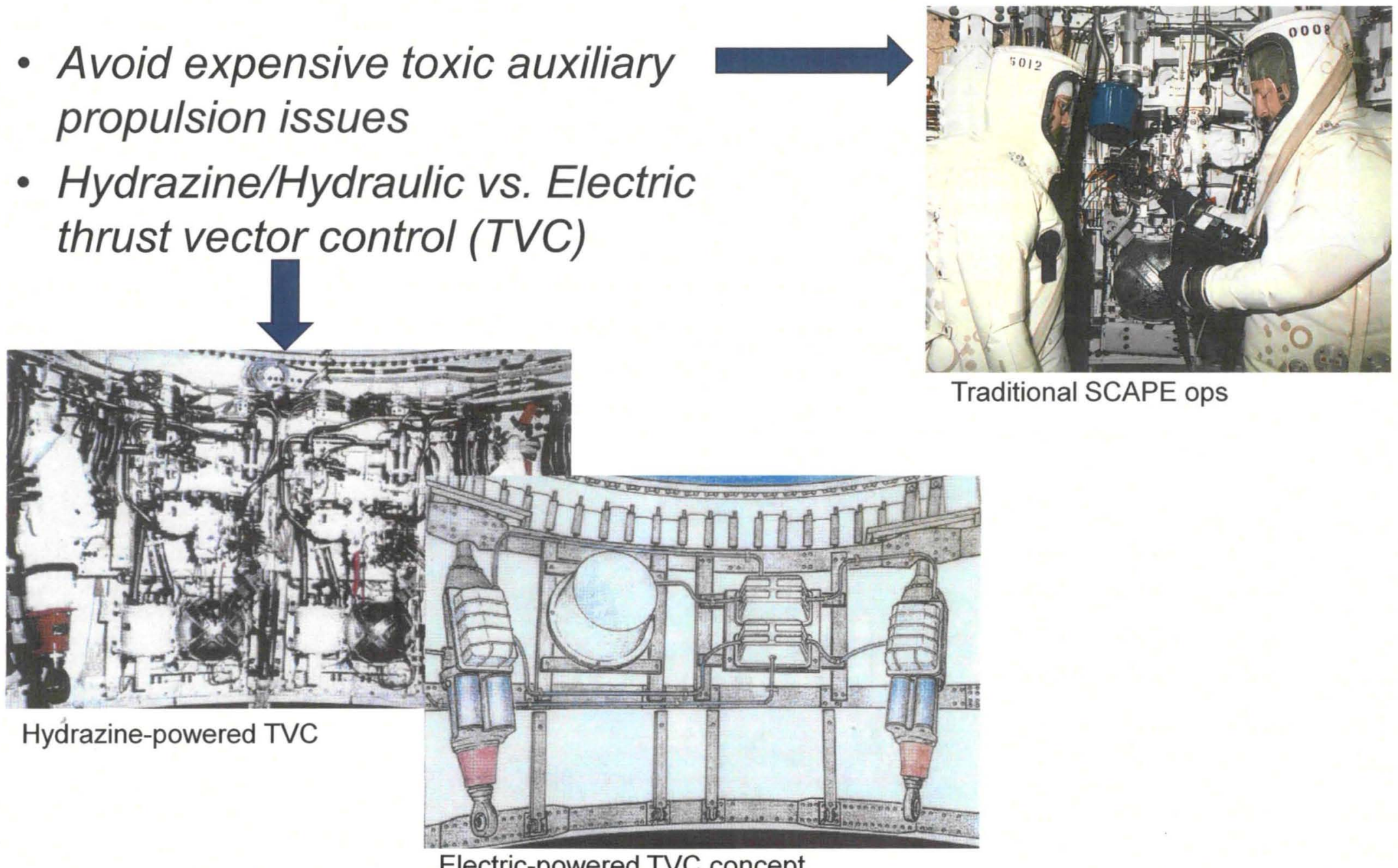

Electric-powered TVC concept 


\section{Conclusion}

- Investments in essential technologies presented can have positive impact on major contributors to life cycle cost through substantial reductions in:

- Work effort and time involved with the design development, testing and evaluation phase

- Recurring production and vendor supply in sustaining the system by design

- Flight and ground infrastructure accumulation by design

- Flight and ground operations work accumulation by design

- Overall launch productivity improvement through major reduction in the critical path time necessary to produce a space flight

- Six-step process described, with suggested technologies and advanced design techniques, represents a high payoff design approach that provides a major step in enabling affordable and sustainable space transportation systems 